\title{
Carbamazepine-Fumaric Acid and Carbamazepine-Succinic Acid Co-crystal Screening Using Solution Based Method
}

\author{
Fatinah Ab Rahman, Syarifah Abd Rahim, Chou C. Tan, Souk H. Low, and Noor Ashila Ramle
}

\begin{abstract}
Co-crystal plays a critical role in the pharmaceutical industry and becoming as an alternative approach to improve the bioavailability of poor water soluble drugs especially for a weakly ionisable groups or neutral compounds. In this study the co-crystal screening was carried out for carbamazepine (CBZ) and co-crystal former (CCF) of fumaric acid (FUM) and succinic acid (SA) using non-stoichiometric method (addition of $\mathrm{CBZ}$ to $\mathrm{CCF}$ saturated solution) and stoichiometric method (evaporation of 1:1 molar ratio of $\mathrm{CBZ}$ to $\mathrm{CCF}$ ) in acetonitrile, ethyl acetate, propanol, ethanol and formic acid solvent systems. The crystals produced from the screening were characterized using Powder X-ray Diffraction (PXRD), Differential Scanning Calorimetry (DSC) and Fourier Transform Infrared (FT-IR). The PXRD analysis had confirmed that the co-crystal was successfully formed in both methods for all of the solvent system studied with an exception to formic acid in the stoichiometric method for CBZ-FUM system and in all methods for CBZ-SA system. The findings from this analysis revealed that Form $A$ and Form $B$ of CBZ-FUM co-crystal had been successfully formed from different solvents systems. DSC analysis had shown that the melting point of CBZ-FUM and CBZ-SA co-crystals were in the range similar to the previous study. The characterization using FT-IR indicated that the functional groups which include amides and carboxylic acids were presented in the co-crystal produced. Further study on the co-crystal solubility and dissolution rate is needed in order to access the efficacy of the co-crystal since the screening methods have been successfully confirmed the formation of the co-crystal.
\end{abstract}

Index Terms-Carbamazepine, co-crystal, stoichiometry, non-stoichiometry.

\section{INTRODUCTION}

Co-crystallisation allows binding two or more crystal component in single crystalline lattice without breaking or making new covalent bonds [1], [2]. Co-crystals can be defined as "a stoichiometric multi-component system which connected by non-covalent interactions and present in solid form under ambient conditions". Pharmaceutical co-crystal is a co-crystal in which at least one of the molecular components is an API and along with the other components called

Manuscript received January 31, 2016; revised October 16, 2017. This work was supported in part by the Ministry of Education Malaysia for supported this work with sufficient grant RDU120114 and Chemical Engineering Laboratory, UMP for equipment and facilities available.

F. Ab Rahman, S. Abd Rahim, C. C. Tan, L. S. Han, and N. A. Ramlee are with the Faculty of Chemical \& Natural Resources Engineering, Universiti Malaysia Pahang, 26300 Gambang, Pahang, Malaysia (e-mail: fatinahabrahman@gmail.com, choang_911@hotmail.com, syarifah@ump.edu.my, ashilaramle@gmail.com) co-crystal formers [3]. The role of co-crystal former help the active drug to disintegrate into small particles to be transported to the blood stream to where the drug is intended to play its role and still protect the product's stability so it will be at greatest benefits and effectiveness [4]. Co-crystals are considering as a major class of pharmaceutical materials to promote the solubility and dissolution. Apart from co-crystals, other materials such as polymorphs, salts, and amorphous solids are also widely used to enhance dissolution and bioavailability of less soluble API [5], [6].

The enhancement of drug solubility is required in the pharmaceutical industry [7]. Solubility is known as the key factors in determining the efficacy as well as the activity of a drug. Nowadays, all of the generic drug manufacturers are competing in the increasingly sophisticated market. The improvement of the drug solubility will dramatically draw their attention as this can make profit towards their business [8]. Hence, the crystal form of APIs is selected to fulfill the requirement. The improvement of the solubility can maximize the bioavailability because poor solubility in water correlates with the poor bioavailability.

Carbamazepine (CBZ) is practically insoluble in water and facing challenges of dissolution-limited bioavailability [3], [9]-[13]. CBZ is a drug that used as anticonvulsant for treatment of epilepsy and trigeminal neuralgia [14]. CBZ can be classified in class 2 drugs under biopharmaceutics classification system (BCS) [15]. Drugs in this class are analyzed to have low solubility in an aqueous media, but having a high permeability via human intestinal membrane [15], [16]. Moreover, CBZ has four different anhydrous polymorph forms and dehydrate forms, and CBZ form III is known as the mainly stable anhydrous form at ambient conditions [17]. Previous study has reported that co-crystals have been successfully formed using slow evaporation, reaction co-crystallisation, solid state grinding and slurry [18]-[23].

Hence, the aim of this study is to investigate the CBZ-FUM and CBZ-SA co-crystal formation using non-stoichiometric method which including continuous shaking and stirring and stoichiometric method of solvent evaporation in different solvent systems (acetonitrile, ethyl acetate, propanol, ethanol and formic acid).

\section{PROCEDURE}

\section{A. Materials}

The CBZ and CCF (FUM and SA) were purchased from 
ECA International Corporation and Sigma-Adrich Company respectively. Whereas, the solvents (acetone, propanol, ethyl acetate, formic acid, acetonitrile and absolute ethanol) were supplied by Fisher Scientific with purity exceeding $99 \%$.

\section{B. Non-stoichiometric Crystallisation}

CBZ solid was added to saturated CCF solution prepared using propanol, ethanol, acetonitrile, ethyl acetate and formic acid in $100 \mathrm{~mL}$ conical flask after equilibrating for 72 hours each at room temperature. The added CBZ solutions were left again to equilibrate for about 72 hours in two conditions i.e. in an automated shaker with $150 \mathrm{rpm}$ at room temperature and stirred using a magnetic stirrer. The precipitate crystal was filtered using vacuum filter and dried at room temperature. All experiments were performed in triplicate.

\section{Stoichiometric Crystallisation}

Stoichiometric method is carried out using solvent evaporation method with 1:1 (CBZ:CCF) molar ratio in 25 $\mathrm{mL}$ of propanol, ethanol, acetonitrile, ethyl acetate and formic acid. The mixture was mixed at room temperature. More solvent was added until the solutes were fully dissolved in any cases where the complete dissolution was not obtained. Once the solute had fully dissolved, another $10 \mathrm{~mL}$ of solvent was added into the final solution before filtered using $0.22 \mu \mathrm{m}$ using syringe filter and withdrawn to $20 \mathrm{~mL}$ vial. The solution is then covered with parafilm (with few holes) and left to evaporate at room temperature. The precipitate crystal formed was filtered using vacuum filter and dried at $30^{\circ} \mathrm{C}$ for 24 hours. All experiments were performed in triplicate.

\section{Powder X-ray Diffraction (PXRD)}

PXRD was used to determine the presence of co-crystal in the samples by showing different peak profiles. A RIGAKU (Miniflex II) diffractometer was operated at the operating conditions as following: $(\mathrm{Cu} \mathrm{K} \alpha$ radiation, voltage $30 \mathrm{kV}$, current $15 \mathrm{~mA}$, step size 0.01 , step time $1 \mathrm{~s}$ and angular range between $3^{\circ}$ and $40^{\circ}$ at $2 \theta$ scales.

\section{E. Differential Scanning Calorimetry (DSC)}

DSC model G1000 with series no. of Q1000-0567 was used to determine the melting point of the co-crystal. The samples (1-3 mg) were crimped in aluminium pans and lid then heated from 30 to $300^{\circ} \mathrm{C}$, under nitrogen purge with flowrate of $50 \mathrm{ml} / \mathrm{min}$ at a heating rate of $10^{\circ} \mathrm{C} / \mathrm{min}$.

\section{F. Fourier Transform Infrared (FT-IR)}

The samples were analysed by FTIR to determine the presence of certain functional groups in a molecule. The analysis was performed using FT-IR with 50 series model attached with the diamond detector at the wave number from $4000-600 \mathrm{~cm}^{-1}$ using 32 scans per spectrum with a resolution 4 $\mathrm{cm}^{-1}$ for each sample.

\section{RESUlt AND DISCUSSION}

\section{A. Powder X-ray Diffraction (PXRD)}

The presence of co-crystal can be identified using PXRD since every crystalline solid phase has its unique PXRD pattern [24]. PXRD pattern profiles produced for all components of CBZ, CCF (FUM and SA) and its co-crystal (CBZ-FUM and CBZ-SA) were compared to ensure that the co-crystal produced does not contain any mixture of either pure component of CBZ or CCF. As shown in Fig. 1, the pure components used in this study were CBZ Form III [17], $\alpha$ polymorph of FUM [25] and $\beta$ polymorph of SA [26].

From the analysis obtained, it was found that CBZ-FUM co-crystal had been successfully formed in stoichiometric and non- stoichiometric methods for all solvents used except for formic acid in stoichiometric method where no crystal was precipitated.

The results pointed that CBZ-FUM has two polymorphic forms i.e. Form A and Form B depending on the type of solvents and methods used. This finding compatible with previous, stated that method used in crystallisation process affect the polymorphic forms of co-crystal produced [23], [27]. CBZ-FUM Form A and Form B was formed from saturated aqueous and near saturated or saturated ethanolic solution respectively [28]. Mole ratios also play a role in determining the polymorphic forms of co-crystal [29]. The pattern profiles for all methods in acetonitrile and ethyl acetate show that the co-crystal possessed Form A. Differ with the usage of formic acid solvent, the co-crystal produced only in non-stoichiometric method was Form B. Different results were obtained in ethanol and propanol. The pattern profile for CBZ-FUM Form A and Form B was resulted in ethanol from stoichiometric method (evaporation condition) and non-stoichiometric method (stirring and shaking conditions) respectively, whereas in propanol, Form A formed from stirring and evaporation conditions while Form B formed from shaking conditions. Fig. 2 shows the pattern profile for both Form A and Form B from all methods in ethanol.

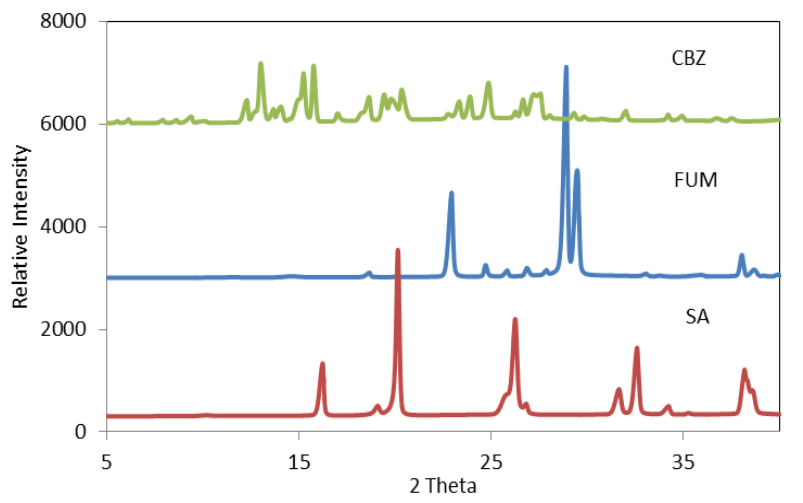

Fig. 1. PXRD pattern profile for pure components.

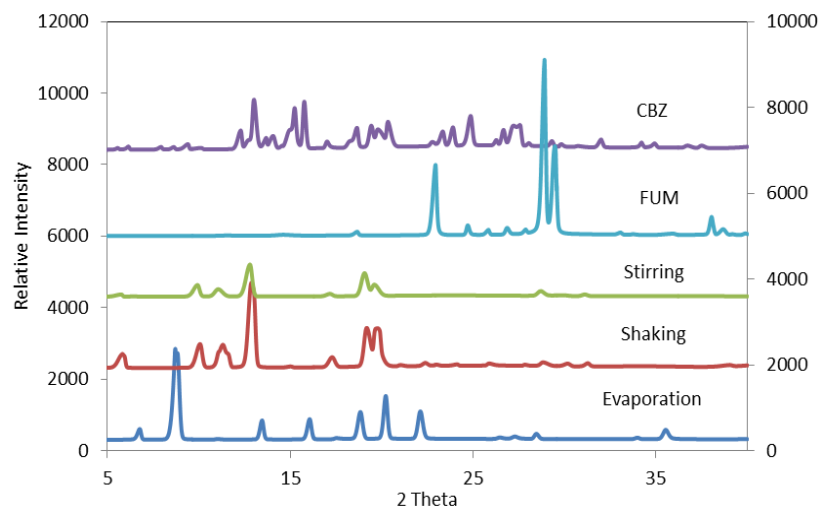

Fig. 2. PXRD pattern profile for stoichiometric (Form A co-crystal) and non-stoichiometric (Form B co-crystal) in ethanol as a solvent. 
Fig. 3 shows the diffraction pattern for CBZ-SA co-crystal in different solvents system. Based on the patterns, diffraction peaks for CBZ-SA in all solvent matched with previous studied conducted by other scholars by $\pm 10 \%$ deviation [23], [30], [31] and does not contain any diffraction peaks of pure components of CBZ and SA which confirms that the powder sample measured was a co-crystal except for formic acid. There were some pattern peaks found in formic acid solvent system that similar to succinic anhydride [26] and CBZ-formic acid solvate [32], therefore it was suspected that there were mixture of both components in the solvent system. However, there is significant different between patterns produced using non-stoichiometric and stoichiometric methods. Solvent evaporation method yields more sharp and prominent peaks due to crystalline nature of the co-crystal produced no agitation and stirring effect involve during the crystallization process [18].

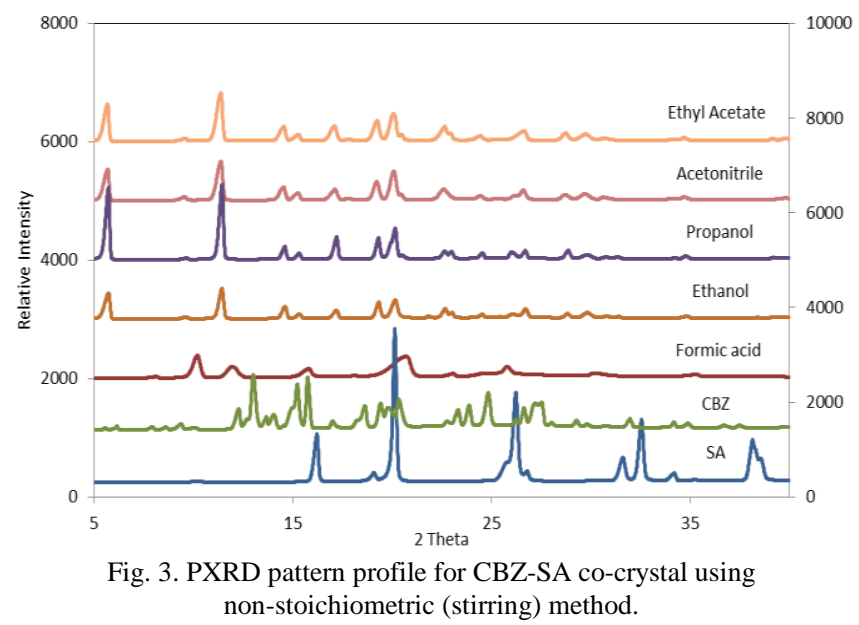

Table I shows the summary of the overall analysis results including the co-crystals formed from acetonitrile, ethyl acetate, formic acid, ethanol and propanol. Table I indicated that the CBZ-FUM co-crystals were successfully formed except for formic acid from solvent evaporation method which was failed to yield either nor, CBZ, FUM and co-crystal. This is presumably that the solubility of CBZ in the solvent medium directly affected the formation of the CBZ, FUM or co-crystal that required as an optimum condition to induce the precipitation of the crystal in solvent evaporation. Meanwhile, CBZ-SA co-crystals were not formed only in formic acid by both methods.

\section{B. Differential Scanning Calorimetry (DSC)}

Based on Fig. 4, the melting point obtained for FUM and SA were $293^{\circ} \mathrm{C}$ and $187^{\circ} \mathrm{C}$ respectively. For CBZ, there is an endothermic peak at $172.19^{\circ} \mathrm{C}$ follow by another peak at $191^{\circ} \mathrm{C}$. Polymorphic transformation of CBZ from Form III to Form I best described the thermal event where polymorphic transformation take place at $162-175^{\circ} \mathrm{C}$ and new phase melted at $189-193^{\circ} \mathrm{C}$ [17] which $191^{\circ} \mathrm{C}$ represent melting point of CBZ Form I. This proved that DSC was important in co-crystal characterization as well as polymorphic characterization, since different polymorph has different melting point.
TABLE I: SUMMARY RESULTS FOR STOICHIOMETRIC AND NON-STOICHIOMETRIC METHOD

\begin{tabular}{lllll}
\hline \hline \multirow{2}{*}{ Solvent } & Screening & CBZ-FUM & CBZ-FUM \\
& Method & Form A & Form B & CBZ-SA \\
\hline \multirow{4}{*}{ Acetonitrile } & Stirring & $\checkmark$ & & $\checkmark$ \\
& Shaking & $\checkmark$ & & $\checkmark$ \\
& Evaporation & $\checkmark$ & & $\checkmark$ \\
\multirow{5}{*}{ Ethyl acetate } & Stirring & $\checkmark$ & & $\checkmark$ \\
& Shaking & $\checkmark$ & & $\checkmark$ \\
& Evaporation & $\checkmark$ & & $\checkmark$ \\
Formic acid & Stirring & & $\checkmark$ & \\
& Shaking & & $\checkmark$ & \\
& Evaporation & & & \\
Ethanol & Stirring & & $\checkmark$ & $\checkmark$ \\
& Shaking & & $\checkmark$ & $\checkmark$ \\
Propanol & Evaporation & $\checkmark$ & & $\checkmark$ \\
& Stirring & $\checkmark$ & & $\checkmark$ \\
& Shaking & & $\checkmark$ & $\checkmark$ \\
\hline \hline
\end{tabular}

CBZ-FUM co-crystal Form A has melting point in the range of $172-176^{\circ} \mathrm{C}$ [21], while Form $\mathrm{B}$ at $186-190^{\circ} \mathrm{C}$ [23], [28], [29]. The increasing in melting point of the two forms possibly due to the crystal packing nature in the CBZ-FUM co-crystal [33]. CBZ-FUM Form $\mathrm{A}$ has an additional endothermic peak at $116-126^{\circ} \mathrm{C}$ which indicate the present of water molecule in the co-crystal [28]. Meanwhile, CBZ-SA co-crystal produced has melting temperature of $188^{\circ} \mathrm{C}$ as shown in Fig. 5. However, additional peak at $120^{\circ} \mathrm{C}$ occurs for system using formic acid as solvent suggested the existence of succinic anhydrate and CBZ-formic acid solvate in the system.

\section{Fourier Transform Infrared (FT-IR)}

Table II represent the summary of peak position in the co-crystal compare with the pure component for propanol solvent. The characteristic peaks of CBZ were observed at $3464,1677,1604$ and $1593 \mathrm{~cm}^{-1}$, compatible with reference [16], [17]. The analysis of FTIR spectrum for CCF revealed peaks at $1659 \mathrm{~cm}^{-1}$ and $3082 \mathrm{~cm}^{-1}$ for FUM whereas 1676 $\mathrm{cm}^{-1}$ and $2931 \mathrm{~cm}^{-1}$ which were assigned to SA $\beta$ polymorph [34].

CBZ-SA exhibit wavelength at 3471, 1698, 1629 and 2790 $\mathrm{cm}^{-1}$, that were in good agreement with the previous [35]. The rest of the solvents and methods used show similar result except for formic acid in all methods. For this solvent, several distinct IR peaks were observed at $3440 \mathrm{~cm}^{-1}$ (amide $\mathrm{N}-\mathrm{H}$ stretch), $3316 \mathrm{~cm}^{-1}$ (C-H stretch, alkene), $1694 \mathrm{~cm}^{-1}(\mathrm{C}=\mathrm{O})$ and $1633 \mathrm{~cm}^{-1}(\mathrm{C}=\mathrm{C})$ that suggested the existence of CBZ-formic acid solvate [32].

The peak profiles in FT-IR spectrum for CBZ-FUM co-crystal was either higher or lower compared to the pure component. The formation of co-crystal can be confirmed by the significant shifting of wavelength [33], [36]. For CBZ-FUM Form A, the peak attribute to the N-H stretch has been shifted to $3455 \mathrm{~cm}^{-1}, 1705 \mathrm{~cm}^{-1}(\mathrm{C}=0), 1601 \mathrm{~cm}^{-1}$ and $1590 \mathrm{~cm}^{-1}$ (N-H bend) for amides meanwhile $3059 \mathrm{~cm}^{-1}(\mathrm{O}-\mathrm{H}$ stretch) and $1656 \mathrm{~cm}^{-1}(\mathrm{C}=0)$ for carboxylic acid. In addition, for CBZ-FUM Form B, the peak for amides have shifted to $3461 \mathrm{~cm}^{-1}$ (N-H stretch), $1682 \mathrm{~cm}^{-1}(\mathrm{C}=\mathrm{O}), 1601 \mathrm{~cm}^{-1}(\mathrm{~N}-\mathrm{H}$ bend) whereas for carboxylic acid show peaks at $3052 \mathrm{~cm}^{-1}$ $\left(\mathrm{O}-\mathrm{H}\right.$ stretch) and $1629 \mathrm{~cm}^{-1}(\mathrm{C}=\mathrm{O})$. 
TABLE II: FT-IR DATA FOR CBZ, FUM, SA AND CO-CRYSTAL BASED ON DIFFERENT SCREENING METHOD USING PROPANOL

\begin{tabular}{|c|c|c|c|c|c|c|c|c|c|}
\hline \multirow{2}{*}{$\begin{array}{l}\text { Functional } \\
\text { group }\end{array}$} & \multirow{2}{*}{ CBZ } & \multirow{2}{*}{ FUM } & \multirow{2}{*}{ SA } & \multicolumn{3}{|c|}{ CBZ-FUM co-crystal } & \multicolumn{3}{|c|}{ CBZ-SA co-crystal } \\
\hline & & & & Shaking & Stirring & Evaporation & Shaking & Stirring & Evaporation \\
\hline \multicolumn{10}{|l|}{ Amides } \\
\hline N-H Stretch & 3464 & - & - & 3461 & 3457 & 3455 & 3470 & 3471 & 3468 \\
\hline $\mathrm{C}=\mathrm{O}$ Stretch & 1677 & - & - & 1679 & 1706 & 1706 & 1698 & 1698 & 1698 \\
\hline \multirow[t]{2}{*}{$\mathrm{N}-\mathrm{H}$ Bend } & 1604 & - & - & 1601 & 1602 & 1602 & 1629 & 1629 & 1627 \\
\hline & 1593 & & & & 1591 & 1590 & & & \\
\hline \multicolumn{10}{|c|}{ Carboxylic acids } \\
\hline O-H Stretch & - & 3082 & 2931 & 3052 & 3057 & 3059 & 2789 & 2790 & 2789 \\
\hline $\mathrm{C}=\mathrm{O}$ Stretch & - & 1659 & 1676 & 1627 & 1660 & 1656 & 1698 & 1698 & 1698 \\
\hline
\end{tabular}

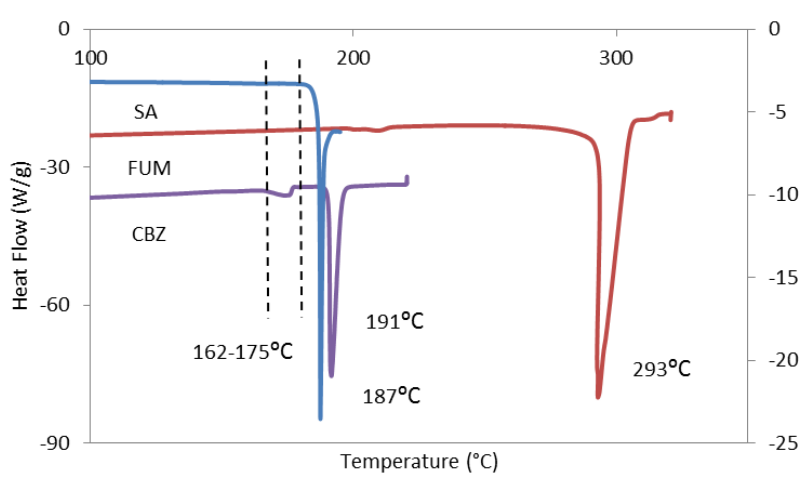

Fig. 4. DSC analysis for pure components of CBZ, FUM and SA.

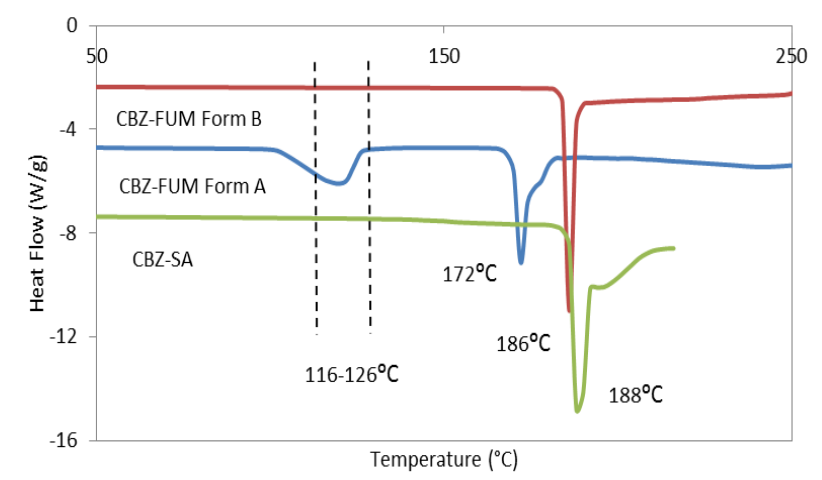

Fig. 5. DSC analysis for shaking in ethyl acetate (CBZ-FUM Form A and CBZ-SA) and shaking in propanol (CBZ-FUM Form B).

\section{CONCLUSION}

The formation of CBZ-FUM and CBZ-SA co-crystals were investigated using non-stoichiometric (continuous shaking and stirring) and stoichiometric (solvent evaporation) methods. The PXRD analysis had confirmed that the CBZ-FUM and CBZ-SA co-crystals were successfully formed in both methods for all of the solvents systems studied with an exception to formic acid in the stoichiometric method for CBZ-FUM system and in all methods for CBZ-SA system. From this analysis it was also shows that CBZ-FUM co-crystal Form A and Form B had been produced from different solvents. This shows that further study in screening is needed for co-crystal formation assessment since there were already many factors proven in affecting the polymorphic transformation of the co-crystal such as different methods, solvent and mole ratio.

\section{REFERENCES}

[1] A. R. Sonawane, S. S. Rawat, and N. N. Janolkar, "Insights of dosage form design: Polymorphs and co-crystals," Asian Journal of Biomedical and Pharmaceutical Sciences, vol. 3, no. 27, pp. 1-8, 2013.

[2] A. Y. Sheikh, S. Abd Rahim, R. B. Hammond, and K. J. Roberts, "Scalable solution cocrystallization: Case of carbamazepine-nicotinamide I," CrystEngComm, vol. 11, pp. 501-509, 2009.

[3] F. L. F. Soares and R. L. Carneiro, "Analysis evaluation of analytical tools and multivariate methods for quantification of co-former crystals in ibuprofen-nicotinamide," Journal of Pharmaceutical and Biomedical Analysis, no. 89, pp. 166-175, 2014.

[4] N. Blagden, M. D. Matas, P. T. Gavan, and P. York, "Crystal engineering of active pharmaceutical ingredients to improve solubility and dissolution rates," Advanced Drug Delivery Reviews, vol. 59, pp. 617-630, 2007.

[5] R. Thakuria, A. Delori, W. Jones, M. P. Lipert, L. Roy, and N. Rodríguez-Hornedo, "Pharmaceutical cocrystals and poorly soluble drugs," International Journal of Pharmaceutics, vol. 453, no. 1 , pp. 101-25, 2013.

[6] S. B. Murdande, M. J. Pikal, R. M. Shanker, and R. H. Bogner, "Solubility Advantage of Amorphous Pharmaceuticals: II. Application of Quantitative Thermodynamic Relationships for Prediction of Solubility Enhancement in Structurally Diverse Insoluble Pharmaceuticals," Pharmaceutical Research, vol. 99, no. 3, pp. 1254-1264, 2010.

[7] S. Kudo and H. Takiyama, "Production method of carbamazepine/saccharin cocrystal particles by using two solution mixing based on the ternary phase diagram," Journal of Crystal Growth, vol. 392, pp. 87-91, 2014.

[8] R. M., Martins, S. Siqueira, L. A. Tacon, and L. A. P. Freitas, "Microstructured ternary solid dispersions to improve carbamazepine solubility," Powder Technology, no. 215-216, pp. 156-165, 2012.

[9] R. Nair, S. Gonen, and S. W. Hoag, "Influence of polyethylene glycol and povidone on the polymorphic transformation and solubility of carbamazepine," International Journal of Pharmaceutics, no. 240, pp. 11-22, 2002.

[10] J. A. H. Junghanns and R. H. Müller, "Nanocrystal technology, drug delivery and clinical applications," International Journal of Nanomedicine, vol. 3, no. 3, pp. 295-309, 2008.

[11] M. Moneghini, I. Kikic, D. Voinovich, B. Perissutti, and J. Filipović-Grčić, "Processing of carbamazepine-PEG 4000 solid dispersions with supercritical carbon dioxide: Preparation, characterisation, and in vitro dissolution," International Journal of Pharmaceutics, no. 222, pp. 129-138, 2001.

[12] K. Gowthamarajan and S. K. Singh, "Dissolution testing for poorly soluble drugs: A continuing perspective," Dissolution Technologies. pp. 24-32, August 2010.

[13] N. Chandel, V. Gupta, A. Pandey, S. Saxena, and S. Choudhary, "Co-crystalization of aceclofenac and paracetamol and their characterization," International Journal of Pharmacy \& Life Sciences, vol. 2, no. 8, 1020-1028, 2011. 
[14] K. Sypek, I. S. Burns, A. J. Florence, and J. Sefcik, "In situ monitoring of stirring effects on polymorphic transformations during cooling crystallization of carbamazepine," Cryst. Growth Des., vol. 12, pp. 4821-4828, 2012.

[15] N. A. Kasim, Marc Whitehouse, C. Ramachandran, M. Bermejo, H. Lennernas, A. S. Hussain, H. E. Junginger, S. A. Stavchansky, K. K. Midha, V. P. Shah, and G. L. Amidon, "Molecular properties of WHO essential drugs and provisional biopharmaceutical classification," Molecular Pharmaceutics, vol. 1, no. 1, pp. 85-96, 2003.

[16] Z. Rahman, C. Agarabi, A. S. Zidan, S. R. Khan, M. A. Khan, "Physico-mechanical and stability evaluation of carbamazepine cocrystal with nicotinamide," American Association of Pharmaceutical Scientists PharmSciTech, vol. 12, no. 2, pp. 693-704, 2011.

[17] A. L. Grzesiak, M. Lang, K. Kim, and A. J. Matzger, "Comparison of the four anhydrous polymorphs of carbamazepine and the crystal structure of form I," Journal of Pharmaceutical Sciences, vol. 92, no. 11, 2260-2271, 2003.

[18] S. G. Fleischman, S. S. Kuduva, J. A. McMahon, B. Moulton, R. D. B. Walsh, N. Rodriguez-Hornedo, and M. J. Zaworotko, "Crystal Engineering of the composition of pharmaceutical phases: Multiple-component crystalline solids involving carbamazepine," Crystal Growth \& Design, vol. 3, no. 6, pp. 909-919, 2003.

[19] S. L. Childs, L. J. Chyall, J. T. Dunlap, V. N. Smolenskaya, B. C. Stahly, and G. P. Stahly, "Crystal engineering approach to forming cocrystals of amine hydrochlorides with organic acids. Molecular complexes of fluoxetine hydrochloride with benzoic, succinic, and fumaric acids," Journal of the American Chemical Society, vol. 126 , no. 41 , pp. 13335-13342, 2004

[20] S. J. Nehm, B. Rodriguez-Spong, and N. Rodriguez-Hornedo, "Phase solubility diagrams of cocrystals are explained by solubility product and solution complexation, "Crystal Growth \& Design, vol. 6, no. 2, pp. 592-600, 2006.

[21] A. V. Trask, W. D. S. Motherwell, and W. Jones, "Physical stability enhancement of theophylline via cocrystallisation" International Journal of Pharmaceutics, vol. 320, no. 1-2, pp. 114-123, 2006.

[22] G. G. Z. Zhang, R. F. Henry, T. B. Borchardt, and X. Lou, "Efficient co-crystal screening using solution-mediated phase transformation," Journal of Pharmaceutical Sciences, vol. 96, no. 5, pp. 990-995, 2007.

[23] S. Abd Rahim, R. B. Hammond, A. Y. Sheikh, and K. J. Roberts, "A comparative assessment of the influence of different crystallization screening methodologies on the solid forms of carbamazepine co-crystals," CrystEngComm, vol. 15, pp. 3862-3873, 2013.

[24] S. Sehić., G. Betz, Š. Hadžidedić, S. K. El-Arini, and H. Leuenberger, "Investigation of intrinsic dissolution behavior of different carbamazepine samples," International Journal of Pharmaceutics, vol. 386, pp. 77-90, 2010.

[25] A. V. Trask, D. A. Haynes, W. D. S. Motherwell, and W. Jones, "Screening for crystalline salts via mechanochemistry," Chem. Commun., pp. 51-53, 2006.

[26] Q. Yu, L. Dang, S. Black, and H. Wei, "Crystallization of the polymorphs of succinic acid via sublimation at different temperatures in the presence or absence of water and isopropanol vapour," J. Cryst. Growth, vol. 340, pp. 209-215, 2012.

[27] M. Kitamura, "Polymorphism in the crystallization of l-glutamic acid," Journal of Crystal Growth, vol. 96, pp. 541-546, 1989.

[28] S. Childs and N. Rodríguez-Hornedo, "Screening strategies based on solubility and solution composition generate pharmaceutically acceptable cocrystals of carbamazepine," Crystengcomm, vol. 10, no. 5, pp. 856-864, 2008.

[29] S. Abd Rahim, F. Ab Rahman, E. N. E. Nasir, and N. A. Ramle, "Carbamazepine co-crystal screening with dicarboxylic acids co-crystal formers," World Academy of Science, Engineering and Technology, International Science Index 101, International Journal of Environmental, Chemical, Ecological, Geological and Geophysical Engineering, vol. 9, no. 5, pp. 425-428, 2015.
[30] M. T. Ansari, H. Pervez, M. T. Shehzad, S. S. U. Hassan, Z. Mehmood, N. H. S. Syed, M. T. Razi, and G. Murtaz, "Improved physicochemical characteristics of artemisinin using sccinic acid," Acta Pol. Pharm. Drug Res., vol. 71, no. 3, pp. 451-462, 2014.

[31] W. Liu, L. Dang, S. Black, and H. Wei, "Solubility of carbamazepine (Form III) in different solvents from (275 to 343) K," J. Chem. Eng. Data, vol. 53, no. 9, 2204-2206, 2008.

[32] J. A. McMahon, "Crystal engineering of novel pharmaceutical forms," Graduate Theses and Dissertations, South Florida, US, 2006.

[33] M. Sevukarajan, B. Thanuja, R. Sodanapalli, and R. Nair, "Synthesis and Characterization of a Pharmaceutical Co-Crystal: (Aceclofenac: Nicotinamide)," Journal of Pharmaceutical Sciences and Research, vol. 3, no. 6, pp. 1288-1293, 2011

[34] N. Issa, S. A. Barnett, S. Mohamed, D. E. Braun, R. C. B. Copley, D. A. Tocher, and S. L. Price, "Screening for cocrystal of succinic acid and 4-aminobenzoic acid," CrystEng Comm, vol. 14, pp. 2454-2464, 2012.

[35] A. Fulias, G. Vlase, T. Vlase, L.-M. Suta, C. Soica, and I. Ledeti, "Screening and characterization of cocrystal formation between carbamazepine and succinic acid," J Therm Anal Calorim, vol. 121, pp. 1081-1086, 2015

[36] Y. Du, H. X. Fang, Q. Zhang, H. L. Zhang, and Z. Hong, "Spectroscopic investigation on cocrystal formation between adenine and fumaric acid based on infrared and raman techniques," Molecular and Biomolecular Spectroscopy, vol. 153, pp. 580-585, 2016.

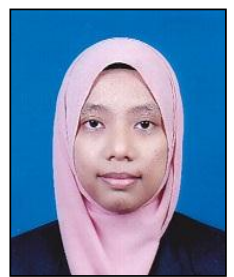

Fatinah Ab Rahman was born on December 15, 1991 at Kota Bharu, Kelantan. She has graduated as a bachelor of chemical engineering in 2014 and currently continues study in Master of Science at Universiti Malaysia Pahang in Kuantan, Pahang. During her bachelor study, she works in the crystallisation field of research majoring in co-crystallisation screening and characterization, and in solubility of co-crystal for master study.

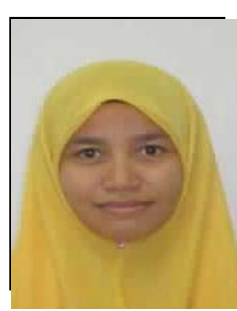

Syarifah Abd Rahim received doctoral degree in process, environmental and materials engineering from the University of Leeds, UK. She is currently a senior lecturer at Faculty of Chemical and Natural Resources Engineering, Universiti Malaysia Pahang, Pahang, Malaysia. As a researcher, she has worked into a research related to the crystallisation, particle technology and wastewater treatment field.

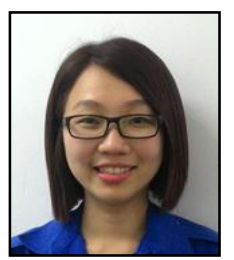

Chao C. Tan was born on January 30, 1991 in Georgetown, Penang. She studied for bachelor of chemical engineering at Universiti Malaysia Pahang in Kuantan, Pahang and has graduated in 2015. During her bachelor study, she worked in the crystallisation field of research majoring in co-crystallisation screening and characterization.

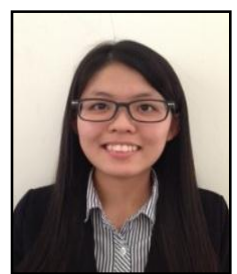

Souk H. Low was born on the August 19, 1991 in Kuala Lumpur, Malaysia. She studied Bachelor of Chemical Engineering at Universiti Malaysia Pahang in Kuantan, Pahang and has graduated in 2015. During her bachelor study, she works in the crystallisation field of research majoring in co-crystallisation screening and characterization. 